\title{
First report of Phytophthora insolita in India
}

\author{
A. K. Das • Ashok Kumar • S. Nerkar • S. Bawage
}

Received: 17 September 2011 / Accepted: 1 August 2012 /Published online: 23 August 2012

(C) Australasian Plant Pathology Society Inc. 2012

\begin{abstract}
During the 2010 monsoon season, Phytophthora insolita was isolated from water accumulated under the canopy of a Nagpur mandarin tree (Citrus reticulata) in Nagpur, Maharashtra State, India. The identity of the isolate was confirmed by morphological and molecular methods. This is the first report of $P$. insolita from India.
\end{abstract}

\section{Keywords Phytophthora insolita $\cdot$ Nagpur Mandarin (Citrus reticulata)}

The genus Phytophthora contains a large diversity of devastating plant pathogenic species which occur in both natural and agricultural systems infecting a broad range of hosts (Erwin and Ribeiro 1996; Judelson and Blanco 2005). Phytophthora species have traditionally been divided into six morphological groups based on features of the sporangium, antheridium, and reproductive behaviour (Newhook et al. 1978; Stamps et al. 1990; Waterhouse 1963). and into 10 clades based on molecular phylogenetic methods (Blair et al. 2008). Citrus is an important subtropical fruit crop prey to this genus. There are 12 Phytophthora species known to infect citrus-: P. boehmeriae, $P$. cactorum, P. capsici, P. cinnamomi, P. citricola, P. citrophthora, $P$. drechsleri, P. hibernalis, P. megasperma, P. palmivora, P. nicotianae and P. syringe (Erwin and Ribeiro 1996). Previously, $P$. insolita and $P$. humicola were isolated from soil in a citrus orchard by baiting soil slurry samples with citrus leaves (Ann and Ko 1980). P. insolita was isolated infrequently from citrus orchards soil in Taiwan, but since then there have been no reports of this species in citrus orchards. In 1998-99, P. insolita

\footnotetext{
A. K. Das $(\bowtie) \cdot$ A. Kumar $\cdot$ S. Nerkar $\cdot$ S. Bawage

National Research Centre for Citrus,

Nagpur 440010 Maharashtra, India

e-mail: dasashiskumar@hotmail.com
}

was reported from forest soil, streams, and ponds of southern China's Hainan Island (Ho et al. 2002). According to Ko and Ann (1985) there is no known natural host for P. insolita; however, it was pathogenic to inoculated apple and cucumber fruits but not to sweet orange or cucumber fruits. $P$. insolita was isolated in Ohio, USA from a Rhododendron necrotic leaf tip (Testa et al. 2005).

During previous studies in a number of citrus orchards in central India covering regions from Maharashtra and Madhya Pradesh states, P. nicotianae, P. palmivora, and P. citrophthora were reported from soils, roots and leaves (Naqvi 2006). Our study was focused on exploring additional Phytophthora spp. associated with citrus orchards in the National Research Centre for Citrus (NRCC), Nagpur, Maharashtra State, India. During the 2010 monsoon season, water samples from NRCC Nagpur Mandarin (Citrus reticulata) orchards were collected and Phytophthora colonies were isolated and purified on PARPH selective medium as previously described (Ali-Shtayeh and MacDonald 1991). Colonies appearing to be Phytophthora were purified and maintained on Corn Meal Agar (CMA) and transferred to carrot agar (CA) for morphological examination. Colony morphology on CA showed a typical chrysanthemum pattern of growth (Fig. 1a). Other morphological characters were observed in petri dishes with subcultured 6-mm agar discs submerged in sterile distilled water incubated at $25{ }^{\circ} \mathrm{C}$ for 5 6 days (Erwin and Ribeiro 1996). Sporangia (length $29.1 \mu \mathrm{m}$, breadth $24.25 \mu \mathrm{m}$, L: B ratio1.20) were observed as terminal, non caducous (persistent), ovoid and non papillate. New sporangia proliferated both externally (Fig. 1b) and internally from older sporangia after zoospores had been released. Intercalary hyphal swelling was also observed. Cultures formed oogonia with prominent oospores (Fig. 1c) on carrot agar but antheridia were absent (a major dichotomous key for $P$. insolita as described by Ho 1992) in both the cases when paired with known P. nicotianae $\mathrm{A} 1$ and $\mathrm{A} 2$ mating types. The mycelia were grown in carrot broth and mycelial DNA was extracted using a Qiagen 
Fig. 1 Morphological characteristics of Phytophthora insolita. a colony morphology on carrot agar medium; $\mathbf{b}$ a germ tube emanating from within an empty sporangium (external proliferation) $\mathbf{c}$ globose, thick-walled oogonia without antheridia
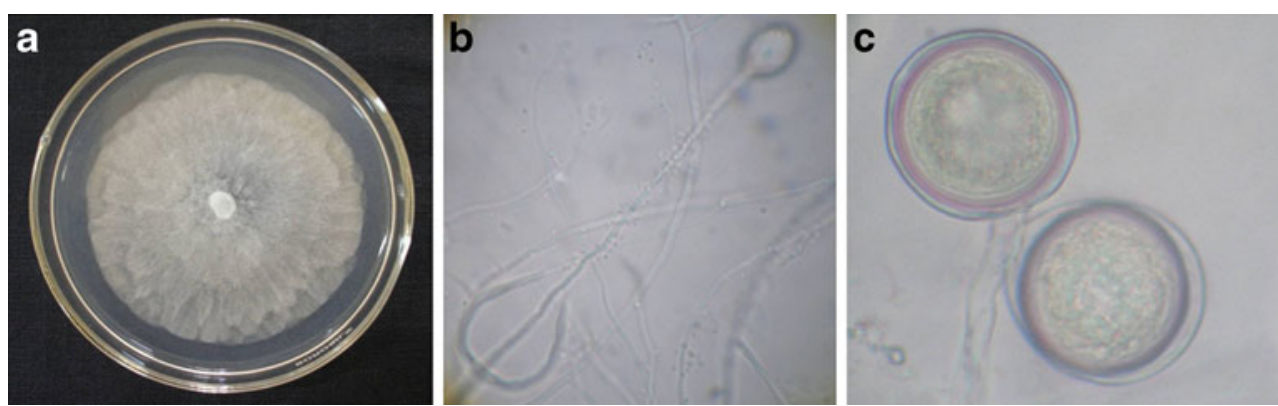

Fig. 2 Formation of watersoaked dark brown lesion on a Nagpur mandarin fruit and $\mathbf{b}$ apple fruit after inoculation with Phytophthora insolita
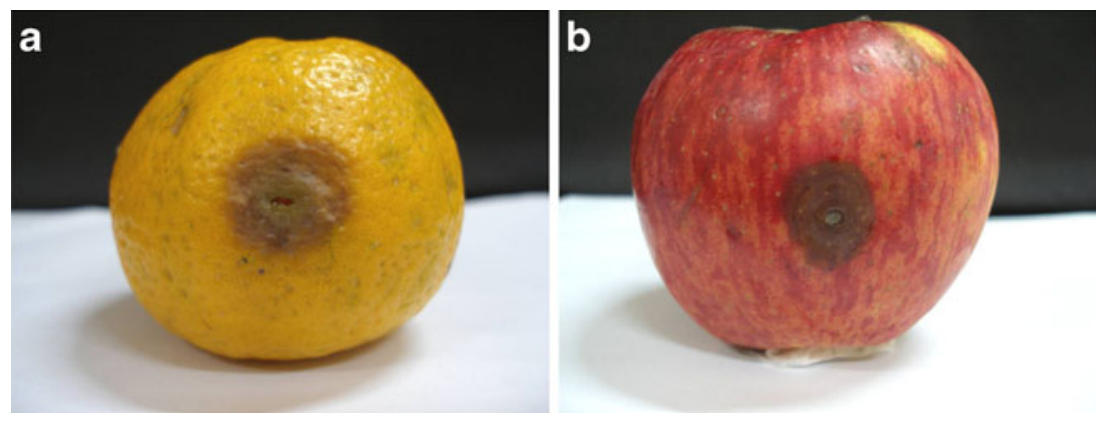

DNeasy Plant mini kit (Qiagen Inc, Valencia, CA) according to manufacturer's instructions. Molecular identification was done by amplifying ITS region of nuclear rDNA using ITS 4 and ITS 6 primer pairs (Cooke et al. 2000) and the PCR product sequenced in both directions at Chromous Biotech, Bangalore, India. The NCBI BLAST search revealed that the isolate was $P$. insolita, having a maximum identity of $97 \%$ with $P$. insolita isolate IMI288805 (Accession no. GU993897). The ITS sequence was submitted to GenBank (Accession JN655559) and the isolate was deposited at the National Research Centre for Citrus, Nagpur (Accession no. NRCPh-119) and at National Bureau of Agriculturally Important Microorganisms (NBAIM), Kusmaur, Mau, India (Accession no. NAIMCCF-03051).

To investigate the pathogenicity, mature fruits of apple, pear, cucumber, acid lime, mandarin orange (Nagpur), sweet orange (Mosambi) were inoculated with $6 \mathrm{~mm} \mathrm{P}$. insolita mycelial agar blocks and with sterile agar blocks as a control. P. insolita inoculation resulted in watersoaked dark brown lesions on apple (Fig. 2b), mandarin orange (Fig. 2a), pear, and acid lime fruit, but not on the cucumber or sweet orange fruit. Control inoculations resulted in no symptoms on any of the inoculated fruit. Koch's postulates were proved by re-isolating the pathogen from the lesions on the inoculated fruits. The re-isolated cultures were morphologically identified using the "agar-disk-in-water" method (Erwin and Ribeiro 1996) as P. insolita. The survival and propagation of this parasitic Phytophthora species in nature is not yet clear, but its occurrence in a mandarin orchard in the current study suggests a possible association with citrus. This is the first record of $P$. insolita in India.
Acknowledgement We acknowledge the funding provided by Indian Council of Agriculture Research (ICAR) under the PhytoFuRa network project to conduct this research.

\section{References}

Ali-Shtayeh MS, MacDonald JD (1991) Occurrence of Phytophthora species in irrigation water in the Nablus area (West Bank of Jordan). Phytopathol Mediterr 30:143-150

Ann PJ, Ko WH (1980) Phytophthora insolita, a new species from Taiwan. Mycologia 72:1180-1185

Blair JE, Coffey MD, Park SY, Geiser DM, Kang S (2008) A multilocus phylogeny for Phytophthora utilizing markers derived from complete genome sequences. Fungal Genet Biol 45:266-277

Cooke DEL, Drenth A, Duncan JM, Wagels G, Brasier CM (2000) A molecular phylogeny of Phytophthora and related oomycetes. Fungal Genet Biol 30:17-23

Erwin DC, Ribeiro OK (1996) Phytophthora diseases worldwide. APS Press, St. Paul

Ho HH (1992) Keys to species of Phytophthora in Taiwan. Plant Pathol Bull (Taiwan) 1:104-109

Ho HH, Zeng HC, Zheng FC (2002) Phytophthora insolita on Hainan island. Bot Bull Acad Sin 43:227-230

Judelson HS, Blanco FA (2005) The spores of Phytophthora: weapons of the plant destroyer. Nat Rev Microbiol 3:47-58

Ko WH, Ann PJ (1985) Phytophthora humicola, a new species from soil of a citrus orchard in Taiwan. Mycologia 77: 631-636

Naqvi SAMH (2006) Distribution of citrus Phytophthora spp. and mating types pathogenic to citrus in central India. J Mycol P1 Pathol 36:44-48

Newhook FJ, Waterhouse GM, Stamps DJ (1978) Tabular key to the species of Phytophthora de Bary. Mycol Papers No. 143

Stamps DJ, Waterhouse GM, Newhook FJ, Hall GS (1990) Revised tabular key to the species Phytophthora. Mycol Papers No. 162

Testa A, Schilb M, Lehman JS, Cristinzio G, Bonello P (2005) First report of Phytophthora insolita and P. infltata in Rhododendron. Plant Dis 89:1128

Waterhouse GM (1963) Key to the species of Phytophthora de Bary. Mycol Papers No. 92. 